\title{
Tuning the Excited-State Dynamics of GFP-Inspired Imidazolone Derivatives
}

\author{
Irina Petkova, ${ }^{*}, \dagger$ Georgi Dobrikov,${ }^{\dagger}$ Natalie Banerji, ${ }^{\ddagger}$ Guillaume Duvanel, ${ }^{\ddagger}$ Robert Perez,, \\ Vladimir Dimitrov, ${ }^{\dagger}$ Peter Nikolov, ${ }^{\dagger}$ and Eric Vauthey ${ }^{*, \dagger}$ \\ Institute of Organic Chemistry with Centre of Phytochemistry, Bulgarian Academy of Sciences, Akad. G. \\ Bontchev str. Bl. 9, Sofia 1113, Bulgaria, and Department of Physical Chemistry, University of Geneva, \\ 30 Quai Ernest-Ansermet, CH-1211 Geneva 4, Switzerland
}

Received: April 28, 2009; Revised Manuscript Received: September 22, 2009

\begin{abstract}
The excited-state dynamics of five derivatives of the GFP-chromophore, which differ by the position and nature of their substituents, has been investigated in solvents of various viscosity and polarity and in rigid media using femtosecond-resolved spectroscopy. In polar solvents of low viscosity, like acetonitrile or methanol, the fluorescence decays of all compounds are multiexponential, with average lifetimes of the order of a few picoseconds, whereas in rigid matrices (polymer films and low temperature glasses), they are single exponential with lifetimes of the order of a few nanoseconds and fluorescence quantum yields close to unity. Global analysis of the fluorescence decays recorded at several wavelengths and of the transient absorption spectra reveals the presence of several excited-state populations with slightly different fluorescence and absorption spectra and with distinct lifetimes. These populations are attributed to the existence of multiple ground-state conformers. From the analysis of the dependence of the excited-state dynamics on the solvent and on the nature of the substituents, it follows that the nonradiative deactivation of all these excited chromophores involves an intramolecular coordinate with large amplitude motion. However, depending on the solvent and substituent, additional channels, namely, inter- and intramolecular hydrogen bond assisted nonradiative deactivation, are operative. This allows tuning of the excited-state lifetime of the chromophore. Finally, an ultrafast photoinduced intramolecular charge transfer is observed in polar solvents with one derivative bearing a dimethylaminophenyl substituent.
\end{abstract}

\section{Introduction}

The green fluorescent protein (GFP) from the jellyfish Aequorea victoria has found widespread applications in molecular biology, cell biology, biochemistry, biotechnology, and molecular genetics. ${ }^{1-5}$ The chromophore responsible for the emission of this protein is $p$-hydroxybenzylideneimidazolinone ( $p$-HBI). The fluorescence arises from its anionic form generated upon ultrafast intramolecular excited-state proton transfer in the neutral form. ${ }^{6-8}$ Although GFP was discovered more than 20 years ago, the photophysics of $p$-HBI and of its mutants is still intensively investigated mainly because of the spectacular decrease of its fluorescence quantum yield, $\Phi_{\mathrm{fl}}$, and lifetime, $\tau$, taking place when going from the protein $\left(\Phi_{\mathrm{fl}}=0.79,{ }^{9} \tau=3.3\right.$ $\mathrm{ns})^{8,10}$ to liquid solutions $\left(\Phi_{\mathrm{fl}}<10^{-3},{ }^{11} \tau<1 \mathrm{ps}\right) .{ }^{12-14}$ In this respect, the photophysical properties of the synthetic dimethyl derivative of the GFP chromophore ( $p$-HBDI $)^{13,15-26}$ and other related model systems ${ }^{24,25,27-32}$ have been extensively investigated.

The absence of fluorescence of $p$-HBDI in solution has been found to originate from an ultrafast internal conversion (IC) from the $\mathrm{S}_{1}$ state. $^{15,16,19,22,33,34}$ Such lack of emission is a characteristic of flexible chromophores like for example triphenylmethane dyes, ${ }^{35-37}$ for which the relevant coordinate for IC is the large amplitude motion of the phenyl rings. However, contrary to these dyes and other chromophores, which also undergo photoisomerization, the fluorescence lifetime and quantum yield of $p$-HBDI were found to exhibit only weak

* To whom correspondence should be addressed, Irina.Petkova@unige.ch (I.P.) and Eric.Vauthey@unige.ch (E.V.).

$\dagger$ Institute of Organic Chemistry with Centre of Phytochemistry.

* Department of Physical Chemistry, University of Geneva. viscosity dependence in moderately viscous solvents. ${ }^{13,16}$ On the basis of this and on quantum chemistry calculations, it has been proposed that $p$-HBDI relaxes nonradiatively to the ground state via a concerted, volume-preserving, twist motion around both bridging bounds, the so-called "hula-twist". ${ }^{15,16}$ On the other hand, substantial viscosity dependence was reported in more viscous solvents, such as polyalcohols. ${ }^{29}$ Additionally to being ultrafast, the excited-state dynamics of $p$-HBDI was also found to be biexponential, with time constants that are the same throughout the emission spectrum but with wavelength-dependent relative amplitudes. ${ }^{14-16}$ This effect has been attributed to the existence of various conformations of the chromophore in the ground state with a similar absorption spectrum. ${ }^{38,39}$ Thus, photoexcitation leads to several $S_{1}$ subpopulations with different lifetimes.

To get a deeper insight into the relaxation mechanism of the GFP chromophore, $p$-HBDI derivatives have been synthesized and their photophysics has been investigated. ${ }^{24,25,27-32}$ For example, Solntsev et al. ${ }^{32}$ have compared the ultrafast excitedstate dynamics of $p$-HBDI and $m$-HBDI in aqueous solutions and have found that the deactivation by large amplitude motion was slower with the $m$-HBDI, due possibly to a higher barrier for $Z / E$ isomerization.

Other authors ${ }^{27-29}$ have also shown that when the methyl groups of $p$-HBDI are replaced by phenyl or other bulky substituents, the fluorescence quantum yield and lifetime exhibit a much more pronounced viscosity dependence. In all these cases, nonexponential excited-state decay, indicative of the existence of several ground state conformers, was found as well.

We report here on our detailed investigation of the photophysics of 4-benzylidene-1,2-diphenyl- $1 \mathrm{H}$-imidazol-5(4H)-one- 
SCHEME 1: Synthesis and Structure of Compounds 1-5
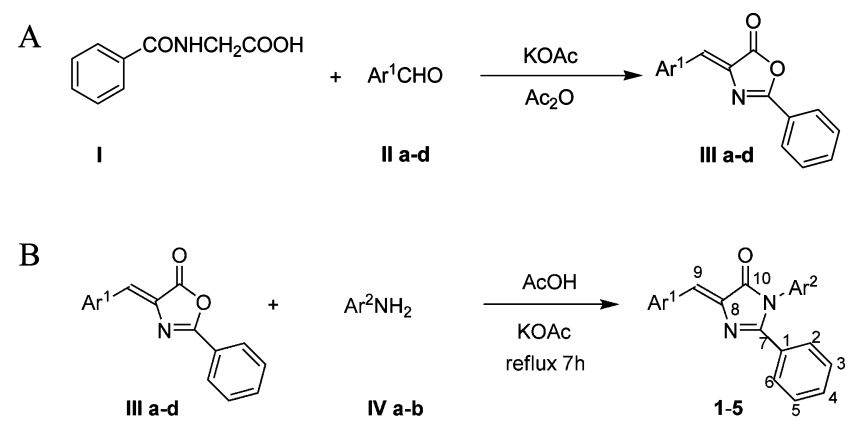
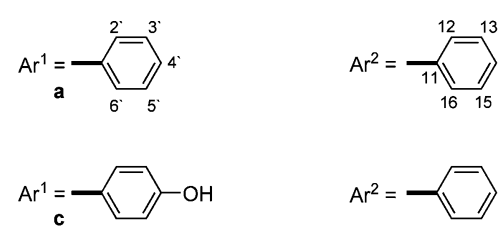

2
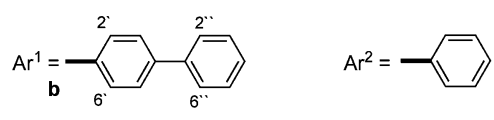

3
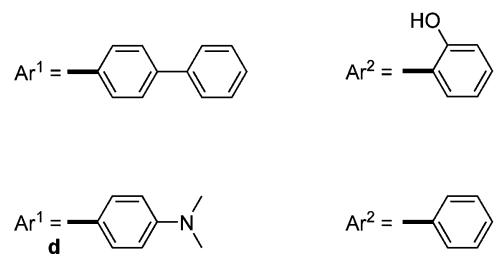

5 derivatives with various substituents in different media using femtosecond-resolved emission and absorption spectroscopy. These substituents differ by their electron donating or withdrawing properties, their size, and their ability for intra- or intermolecular hydrogen bonding (Scheme 1, compounds 1-5). Our main goal was to establish all the different nonradiative deactivation pathways of these fluorophores not only to get a deeper insight into the origin of the weak fluorescence of the GFP chromophore in solution but also to find out whether it is possible to control them in order to develop new fluorophores with tunable emission properties. Indeed, the widespread interest on GFP and its mutants has been particularly focused on their role in biology. As yet, it has not been fully realized that GFPlike fluorophores could have a large potential in optoelectronics, for example, as emitters in organic light-emitting diodes. ${ }^{40}$

\section{Experimental Section}

Samples. The different substituted imidazolone derivatives have been synthesized according to Scheme 1 (see also Supporting Information). The first step includes the preparation of (Z)-2-phenyl-4-(arylmethylene)oxazol-5(4H)-ones by implementation of the classic Erlenmeyer synthesis-condensation of hippuric acid I with the aromatic aldehydes IIa-d in the presence of anhydrous KOAc in acetic anhydride to obtain the corresponding ( $\mathrm{Z}$ )-2-phenyl-4-(arylmethylene)oxazol-5(4H)-ones IIIa-d in moderate yields (Scheme 1A). ${ }^{41-46}$ As known in literature, ${ }^{47-51}$ small amounts of $(E)$-2-phenyl-4-(arylmethylene)oxazol-5(4H)-ones were detected in the crude product by TLC. The appropriate crystallization resulted to the pure target Z-isomers IIIa-d. Although oxazolones are well-known for their good fluorescent properties, ${ }^{52}$ they are mainly used as intermediates. This limitation is caused by their hydrolytical instability in water and in other protic solvents, leading to ringopening $^{53}$ and loss of fluorescent properties. Alternative synthetic methods have also been reported in literature, ${ }^{54-61}$ a microwaveassisted synthesis of azalactones has been recently published. ${ }^{62}$

In a second step, the pure intermediates IIIa-d were heated with the aromatic amines IVa,b and anhydrous KOAc in acetic acid $(\mathrm{AcOH})$ to afford the desired (Z)-2-phenyl-1-(aryl)-4(arylmethylene)-1H-imidazol-5(4H)-ones $(\mathbf{1}-\mathbf{5})$ (Scheme 1B). ${ }^{58-69}$ After column chromatography and/or crystallization, the products $\mathbf{1}$ and 3-5 were obtained as chemically and stereoisomerically pure $Z$-isomers in moderate to high yields. For compound 2 we observed mixtures of $Z / E$-isomers (by NMR), which could not be isolated into the individual stereoisomers. Besides, compound $\mathbf{2}$ is extremely insoluble in low polarity solvents and only weakly soluble in polar solvents. For the imidazolones $\mathbf{1}$ and $\mathbf{5}$ there are previously published data. ${ }^{58,62,65,68-73}$

The solvents, acetonitrile (ACN), propionitrile ( $\mathrm{PrCN})$, butyronitrile $(\mathrm{BuCN})$, methanol $(\mathrm{MeOH})$, ethanol $(\mathrm{EtOH})$, pentanol $(\mathrm{PeOH})$, diethyl ether $\left(\mathrm{Et}_{2} \mathrm{O}\right), n$-hexane $(\mathrm{HX})$, cyclohexane $(\mathrm{CH})$, decalin (DEC), and methylcyclohexane $(\mathrm{MCH})$ were of the highest commercially available purity and were used as received.

Poly(methyl methacrylate) (PMMA) films were prepared as follows: $300 \mathrm{mg}$ of PMMA was dissolved in $10^{-4} \mathrm{M}$ dichloromethane solutions of the investigated compounds. The solutions were poured in Petri dishes, and the solvent was evaporated for about $24 \mathrm{~h}$. The thickness of the resulting films was uniform $(40-50 \mu \mathrm{m})$, and the concentration of the investigated compounds was about $0.500-0.700 \%$ weight.

Steady-State Measurements. Steady-state absorption spectra were recorded with a Perkin-Elmer Lambda $25 \mathrm{UV}-$ vis spectrophotometer set to $1 \mathrm{~nm}$ resolution. Corrected steadystate fluorescence and excitation spectra were measured with a Perkin-Elmer LS 55 spectrofluorometer, with $10 \mathrm{~nm}$ excitation and emission slit widths. The fluorescence quantum yields were determined at room temperature using solute concentrations adjusted to achieve an optical density of 0.1 at the excitation wavelength. The fluorescence standard for compounds 1-4 was $p$-methoxy-benzylidenphtalide in ethanol $\left(\Phi_{\mathrm{fl}}=0.14\right)^{74}$ and for compound 5, coumarin in ethanol $\left(\Phi_{\mathrm{fl}}=0.78\right) .{ }^{75}$

The emission spectra in polymer films were measured in the reflection mode.

The low-temperature luminescence measurements were performed at $77 \mathrm{~K}$ with the standard phosphorescence accessory of a Perkin-Elmer spectrofluorimeter MPF 44 using $4 \mathrm{~mm}$ diameter quartz tubes, and the spectra were subsequently corrected.

Time-Resolved Fluorescence Measurements. Fluorescence dynamics on the subnanosecond time scale was measured by up-conversion using a setup described in detail elsewhere. ${ }^{76,77}$ Excitation was achieved at $400 \mathrm{~nm}$ with the frequency-doubled output of a Kerr lens mode-locked Ti:sapphire laser (Tsunami, Spectra-Physics). The output pulses centered at $800 \mathrm{~nm}$ had duration of $100 \mathrm{fs}$ and a repetition rate of $82 \mathrm{MHz}$. The polarization of the pump beam was at magic angle relative to that of the gate pulses at $800 \mathrm{~nm}$. Experiments were carried out in a $1 \mathrm{~mm}$ rotating cell. The full width at half-maximum (fwhm) of the instrument response function (IRF) was ca. 280 fs. No significant degradation of the samples was observed after the measurements.

Fluorescence decay measurements on a longer time scale were performed using the time-correlated single photon counting (TCSPC) technique. Excitation was carried out at a repetition rate of $40 \mathrm{MHz}$ with $<90$ ps pulses generated by laser diodes 


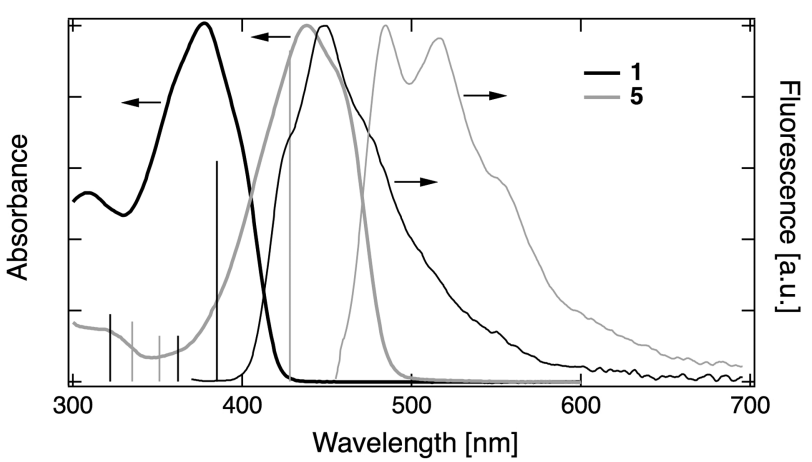

Figure 1. Absorption and fluorescence spectra of $\mathbf{1}$ and $\mathbf{5}$ in cyclohexane at $300 \mathrm{~K}$. The vertical lines denote the computed energies of the $\pi \pi^{*}$ transitions and the corresponding relative oscillator strengths of the Z-conformer.

either at $395 \mathrm{~nm}$ (PicoQuant model LDH-PC-400B) or at 469 nm (PicoQuant model LDH-PC-470). Fluorescence was collected at $90^{\circ}$ and was measured at magic angle with respect to the polarization of the pump pulses. A 420 or $560 \mathrm{~nm}$ cutoff filter placed in front of the photomultiplier tube (Hamamatsu, H5783-P-01) ensured that no scattered excitation light could reach the detector, whose output was connected to the input of a TCSPC computer board module (Becker and Hickl, SPC-30012). The fwhm of the IRF was around $200 \mathrm{ps.}$

Transient Absorption (TA) Measurements. Most of the TA measurements have been carried out with the setup described in detail in ref 78. Additional measurements have been performed with an upgraded version of this setup as discussed in ref 79 that gives a better signal/noise ratio. Excitation was performed at $400 \mathrm{~nm}$ using the frequency-doubled output of a standard $1 \mathrm{kHz}$ amplified Ti:sapphire system (Spectra-Physics). The pump intensity on the sample was around $2 \mathrm{~mJ} / \mathrm{cm}^{2}$. The polarization of the probe pulses was at magic angle relative to that of the pump pulses. All spectra were corrected for the chirp of the white light probe pulses. The fwhm of the IRF was ca. $200 \mathrm{fs}$. The sample solutions were placed in a $1 \mathrm{~mm}$ path length quartz cell where they were continuously stirred by $\mathrm{N}_{2}$-bubbling. Their absorbance at the excitation wavelength was between 0.05 and 0.2 , depending on the solvent.

Computational Methods. The ground-state singlet gas-phase geometries of $\mathbf{1 - 5}$ were fully optimized at the density functional level of theory (DFT) ${ }^{80}$ using the B3-LYP functional, ${ }^{81,82}$ and a def-TZVP ${ }^{83}$ basis set. Electronic vertical excitation energies and oscillator strengths were then computed with time-dependent density functional theory (TDDFT) using the same functional and basis set. All calculations were performed using the TURBOMOLE 5.8 package. ${ }^{84-87}$

\section{Results}

Steady-State Spectroscopy. The UV-vis absorption spectra of 1-4 above $300 \mathrm{~nm}$ are very similar and consist of a broad band with a maximum located between 375 and $400 \mathrm{~nm}$ depending on the nature of the $\mathrm{Ar}^{1}$-substituent and with a shoulder at shorter wavelength (Figure 1). The presence of electron-withdrawing or electron-donating substituents in $\mathbf{2 , 3}$, and 4 leads to a bathochromic shift of the Frank-Condon absorption transition up to $550 \mathrm{~cm}^{-1}$ (Table 1). Furthermore, the strong electron-donating group in $\mathbf{5}$ results to a red shift of the longest wavelength absorption band of more than $3600 \mathrm{~cm}^{-1}$ (Table 1, Figure 1).

These spectra point to a coupling between the $\mathrm{Ar}^{1}$-substituents and the imidazolone moiety in all compounds, the strongest interaction being between the (dimethylamino)phenyl and the carbonyl groups in $\mathbf{5}$.

A very weak solvatochromism was observed with 1-4: compared to $\mathrm{CH}$, the absorption maximum in ACN is slightly blue-shifted, whereas in ethanol the maximum is red-shifted. The number of solvents investigated is not large enough to allow precise interpretation of this small solvent dependence. Nevertheless, the blue shift in ACN might be due to the lower refractive index of this solvent, thus to weaker dispersion interaction, while the red shift in EtOH might originate from hydrogen bonding interaction. By contrast, the first absorption band of 5 exhibits a substantial bathochromic shift $\left(1300 \mathrm{~cm}^{-1}\right)$ by going from the nonpolar $\mathrm{CH}$ to the polar $\mathrm{ACN}$ and $\mathrm{EtOH}$. In this case, the shift from $\mathrm{CH}$ to $\mathrm{ACN}$ is attributed to dipole-dipole interaction, whereas the additional shift in $\mathrm{EtOH}$ is tentatively assigned to the effect of hydrogen bonding.

In PMMA films, the shape and the position of the longest wavelength absorption band of $\mathbf{1 - 5}$ are very similar to those measured in EtOH (Table 1).

The fluorescence spectra of $\mathbf{1 - 4}$ in all solvents investigated are characterized by a Stokes shift amounting to about 4000 $\mathrm{cm}^{-1}$. Furthermore the fluorescence spectrum is independent of the excitation wavelength and does not exhibit a strong solvatochromism. The red shift introduced by the $\mathrm{Ar}^{1}-$ and $\mathrm{Ar}^{2}-$ substituents can be as large as $990 \mathrm{~cm}^{-1}$ in both nonpolar and polar media and is thus more pronounced than that found in the absorption spectra.

On the other hand, the fluorescence spectrum of $\mathbf{5}$ is strongly solvent dependent (Figure 2). In $\mathrm{CH}$, a pronounced vibrational structure is observed. As solvent polarity increases, this structure vanishes and the fluorescence maximum shifts to longer wavelengths (Figure 2). This effect suggests a substantial solvent and/or intramolecular reorganization of the excited state in polar solvents.

The fluorescence quantum yields, $\Phi_{\mathrm{fl}}$, of $\mathbf{1}$ and $\mathbf{3}$ in $\mathrm{CH}$ are around $10^{-2}$, whereas those of the other compounds are about $10^{-3}$ (Table 1). The fluorescence quantum yields of $\mathbf{1 - 3}$ in protic and aprotic polar solvents $(\mathrm{EtOH}, \mathrm{ACN})$ decrease substantially, whereas those of $\mathbf{4}$ and $\mathbf{5}$ remain essentially unchanged.

The fluorescence spectra of all compounds in frozen EtOH matrix at $77 \mathrm{~K}$ are very similar to those in room temperature liquids; however, the fluorescence quantum yields are much larger and for $\mathbf{1}, \Phi_{\mathrm{fl}}$ amounts to unity (Table 1). This is in agreement with the observed increase of the fluorescent intensity in PMMA films as well. Finally no phosphorescence could be detected with all compounds investigated even at $77 \mathrm{~K}$.

Time-Resolved Fluorescence. Fluorescence up-conversion measurements of $\mathbf{1 - 5}$ in various solvents were performed at several wavelengths throughout the emission band. As shown in Figure $3 \mathrm{~A}$ for $\mathbf{3}$ in $\mathrm{ACN}$, the fluorescence dynamics exhibits substantial wavelength dependence, accelerating with increasing wavelength. In order to get a deeper insight into the origin of this effect, these time profiles were analyzed globally with a sum of exponentials as trial function. Once the global lifetime was determined, the amplitudes of the different decay components were calculated by rescaling the integrated time profiles according to the stationary fluorescence intensity, as explained in ref 88. The data shown in Figure 3A could be satisfactory reproduced using the convolution of the instrument response function with the sum of three exponential functions with time constants of $0.4,1.2$, and 11.9 ps. As illustrated in Figure 3B, the shortest time constant is associated with a decay of the fluorescence intensity at short wavelength and with a rise above 
TABLE 1: Absorption, $\lambda_{\mathrm{abs}}$, and Fluorescence, $\lambda_{\mathrm{ff}}$, Maxima in $\mathrm{nm}$ and Fluorescence Quantum Yields, $\boldsymbol{\Phi}_{\mathrm{fl}}$, of $1-5$

\begin{tabular}{|c|c|c|c|c|c|c|c|c|c|c|c|c|c|}
\hline & \multirow{2}{*}{\multicolumn{3}{|c|}{$\frac{\text { cyclohexane }}{300 \mathrm{~K}}$}} & \multirow{2}{*}{\multicolumn{3}{|c|}{$\frac{\text { acetonitrile }}{300 \mathrm{~K}}$}} & \multicolumn{5}{|c|}{ ethanol } & \multirow{2}{*}{\multicolumn{2}{|c|}{$\frac{\text { PMMA }}{300 \mathrm{~K}}$}} \\
\hline & & & & & & & \multicolumn{3}{|c|}{$300 \mathrm{~K}$} & \multicolumn{2}{|c|}{$77 \mathrm{~K}$} & & \\
\hline & $\lambda_{\mathrm{abs}}$ & $\lambda_{\mathrm{ff}}$ & $\Phi_{\mathrm{fl}}$ & $\lambda_{\text {abs }}$ & $\lambda_{\mathrm{fl}}$ & $\Phi_{\mathrm{fl}}$ & $\lambda_{\mathrm{abs}}$ & $\lambda_{\mathrm{fl}}$ & $\Phi_{\mathrm{fl}}$ & $\lambda_{\mathrm{fl}}$ & $\Phi_{\mathrm{fl}}$ & $\lambda_{\mathrm{abs}}$ & $\lambda_{\mathrm{fl}}$ \\
\hline 2 & 389 & 458 & 0.005 & 393 & 470 & $<10^{-3}$ & 403 & 475 & $<10^{-3}$ & 485 & $\sim 0.2$ & 400 & 465 \\
\hline 3 & 396 & 470 & 0.03 & 393 & 471 & 0.002 & 397 & 470 & 0.002 & 470 & $\sim 0.3$ & 400 & 470 \\
\hline 4 & 396 & 470 & 0.001 & 393 & 470 & 0.003 & 396 & 471 & 0.003 & 470 & $\sim 0.2$ & $a$ & $a$ \\
\hline
\end{tabular}

${ }^{a}$ Measurements not performed.

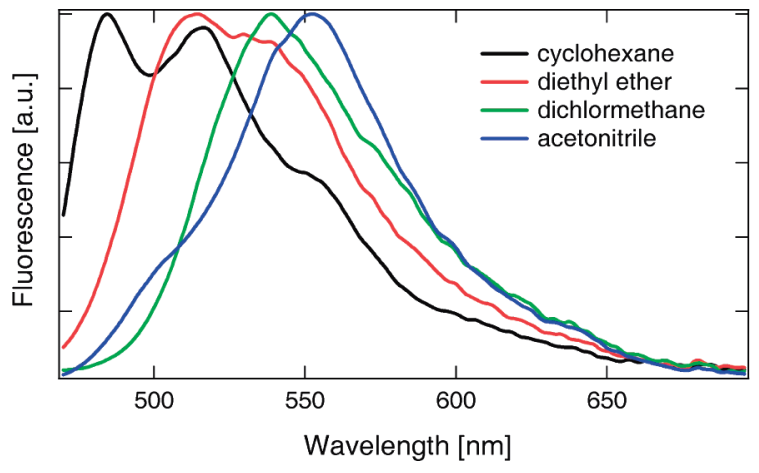

Figure 2. Fluorescence spectra of $\mathbf{5}$ at $300 \mathrm{~K}$ in various solvents.
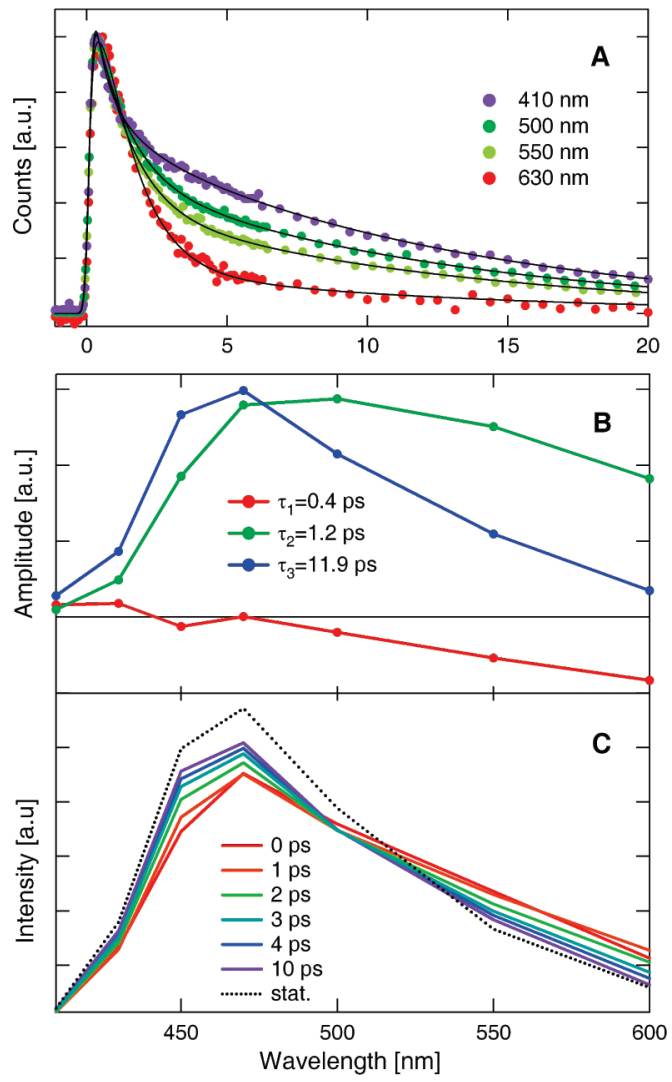

Figure 3. (A) Fluorescence time profiles of $\mathbf{3}$ in acetonitrile. (B) Decayassociated spectra obtained from the global analysis of the fluorescence dynamics of $\mathbf{3}$ in acetonitrile. (C) Reconstructed area-normalized timeresolved emission spectra and stationary spectrum (dotted).

about $470 \mathrm{~nm}$. This corresponds essentially to a red shift of the fluorescence band but not to a decay of the excited-state population. Considering that the 0.4 ps time constant is close to the solvation time of $\mathrm{ACN},{ }^{89}$ this process can be assigned to a dynamic Stokes shift. However, excitation is performed at $400 \mathrm{~nm}$, and about $0.2 \mathrm{eV}$ is deposited in $\mathbf{3}$ as vibrational energy.
As vibrational relaxation results to spectral dynamics as well, mostly as a narrowing of the emission band, ${ }^{90}$ it could also contribute to the $0.4 \mathrm{ps}$ component. On the other hand, the amplitude factors of the two larger time constants are positive at all wavelengths and their spectral dependences, especially that associated with the longest one, resemble that of the stationary fluorescence spectrum. Consequently, these two components correspond to a decay of the excited-state population. A biexponential population decay can be due to two distinct emitting populations. However, it has also been shown that a Gaussian distribution of decay times associated with a distribution of different populations can also be reproduced by a biexponential function. ${ }^{91,92}$ Independently of whether the decay is due to two or to a distribution of populations, the resemblance of the associated amplitude spectra points to emitting species with relatively similar fluorescence spectra.

The best-fit parameters have been used to reconstruct timeresolved emission spectra, those shown in Figure $3 \mathrm{C}$ having been area-normalized to better distinguish the spectral changes occurring during the first few picoseconds. The main feature is a marked narrowing of the red side of the band. This change can be explained by the slightly red-shifted emission spectrum of the shorter-lived species compared to that of the long-lived one.

Qualitatively similar fluorescence dynamics was observed in the other nitrile solvents, the main difference being that all time constants are larger than those in ACN (Table 2). In alcohols on the other hand, the time profiles could not be correctly reproduced with less than four exponential functions, one accounting for the initial spectral dynamics and the other three corresponding to population decays. Four exponentials were also used in the nonpolar $\mathrm{CH}$ and DEC, but in this case the initial spectral dynamics with a time constant $\tau_{1}$ should rather be ascribed to the relaxation of intramolecular modes.

As the amplitude spectra of the population components are all quite similar, an amplitude average population decay time was calculated as

$$
\langle\tau\rangle=\sum_{i>1} a_{i} \tau_{i} / \sum_{i>1} a_{i}
$$

where $a_{i}$ is the amplitude of the component $i$ at a fixed wavelength, in general at the stationary fluorescence maximum. Table 2 shows that, if the average population decay times of $\mathbf{3}$ are sorted according to the class of solvents, namely, nitriles, alcohols, and nonpolar solvents, $\langle\tau\rangle$ increases with solvent viscosity within each class. Moreover, at constant viscosity, $\langle\tau\rangle$ is the shortest in alcohols and is clearly the largest in nonpolar solvents.

The fluorescence dynamics of the other compounds was measured in the same way in various solvents, and the data were also analyzed globally, except for $\mathbf{1}$ for which the fluorescence was measured at the maximum wavelength only. 
TABLE 2: Time Constants Obtained from a Global Analysis of the Fluorescent Time Profiles of 1-5 Measured at Different Wavelengths

\begin{tabular}{|c|c|c|c|c|c|c|}
\hline & solvent & $\tau_{1}(\mathrm{ps})$ & $\tau_{2}(\mathrm{ps})$ & $\tau_{3}(\mathrm{ps})$ & $\tau_{4}(\mathrm{ps})$ & $\langle\tau\rangle(\mathrm{ps})$ \\
\hline \multirow[t]{5}{*}{$\mathbf{1}^{a}$} & acetonitrile & $0.5(0.35)^{b}$ & $1.1(0.19)$ & $22.1(0.43)$ & & \\
\hline & ethanol & $0.5(0.53)$ & $3.7(0.26)$ & $23.6(0.21)$ & & \\
\hline & pentanol & $0.6(0.51)$ & $6.3(0.30)$ & $56.0(0.19)$ & & \\
\hline & $n$-hexane & $0.4(0.52)$ & $1.4(0.19)$ & $115.0(0.29)$ & & \\
\hline & cyclohexane & $0.4(0.49)$ & $1.9(0.20)$ & $108.0(0.31)$ & & \\
\hline \multirow[t]{3}{*}{2} & acetonitrile & $<\mathrm{IRF}^{c}$ & 0.4 & 2.0 & & 1.1 \\
\hline & ethanol & $<\mathrm{IRF}$ & 0.5 & 2.2 & & 1.6 \\
\hline & cyclohexane & $<\mathrm{IRF}$ & 0.8 & 10.6 & & 6.1 \\
\hline \multirow[t]{8}{*}{3} & acetonitrile & 0.4 & 1.2 & 11.9 & & 4.6 \\
\hline & propionitrile & 0.3 & 1.7 & 18.9 & & 12.2 \\
\hline & butyronitrile & $<\mathrm{IRF}$ & 2.6 & 27.6 & & 16.3 \\
\hline & methanol & 0.4 & 1.6 & 6.0 & 24.9 & 4.8 \\
\hline & ethanol & 0.2 & 0.5 & 2.1 & 13.2 & 6.2 \\
\hline & pentanol & $<\mathrm{IRF}$ & 1.4 & 8.7 & 45.1 & 16.3 \\
\hline & cyclohexane & $<\mathrm{IRF}$ & 0.6 & 7.0 & 128.3 & 51.3 \\
\hline & decalin & $<\mathrm{IRF}$ & 1.3 & 11.9 & 212.2 & 107.5 \\
\hline \multirow[t]{6}{*}{4} & acetonitrile & 0.27 & 1.8 & 12.9 & & 7.3 \\
\hline & butyronitrile & 0.6 & 3.3 & 38.1 & & 22.1 \\
\hline & ethanol & $<\mathrm{IRF}$ & 0.5 & 2.5 & 13.2 & 5.7 \\
\hline & pentanol & $<\mathrm{IRF}$ & 0.8 & 6.6 & 42.0 & 15.4 \\
\hline & cyclohexane & $<\mathrm{IRF}$ & 0.5 & 13.7 & & 3.0 \\
\hline & $n$-hexane & $<\mathrm{IRF}$ & 1.6 & 28.3 & & 11 \\
\hline \multirow[t]{4}{*}{5} & acetonitrile & 0.2 & 0.9 & 11.0 & & \\
\hline & butyronitrile & $<\mathrm{IRF}$ & 1.1 & 14.8 & & \\
\hline & ethanol $^{a}$ & $<\mathrm{IRF}$ & $1.2(0.52)$ & $8.6(0.48)$ & & \\
\hline & cyclohexane $^{a}$ & $0.8(0.48)$ & $9.4(0.45)$ & $25.6(0.07)$ & & \\
\hline
\end{tabular}

For this compound, a reliable assignment of the time constants obtained from the multiexponential fit is therefore not possible. The resulting time constants are listed in Table 2 .

Although 1 was not investigated in detail, the solvent dependence of its fluorescence dynamics does not differ much from that of $\mathbf{3}$. The same is true for $\mathbf{2}$, except that the average lifetime is faster than for $\mathbf{3}$ in all three types of solvents, especially in $\mathrm{CH}$.

On the other hand, $\mathbf{4}$ behaves similarly to $\mathbf{3}$ in nitriles and alcohols but exhibits a much faster excited-state dynamics in nonpolar solvents. In fact, the fastest population decay was measured in $\mathrm{CH}$.

Finally, the largest wavelength dependence was found with 5 in polar solvents (Figure 4A). The amplitude spectrum associated with the shortest time constant, $\tau_{1}=0.2 \mathrm{ps}$, points to a substantial dynamic Stokes shift (Figure 4B). However, the reconstructed, area-normalized, time-resolved emission spectra reveal a conversion between two different emitting species rather than a continuous spectral shift, as observed with the other compounds (Figure 4C). The excited-state dynamics of $\mathbf{5}$ seems therefore to differ considerably from that of the other compounds. Because of the probable presence of different species with more distinct emission spectra, an average population decay time cannot really be determined with $\mathbf{5}$.

The fluorescence dynamics in solid matrices is much slower than those in room temperature liquids and could thus be measured by TCSPC. The fluorescence decays in both PMMA films and EtOH glasses at $77 \mathrm{~K}$ could be well reproduced using single exponential functions with lifetimes, $\tau$, around $2.5 \mathrm{~ns}$ (Figure S1 in Supporting Information). The latter together with the radiative time constants, $\tau_{\mathrm{r}}$, calculated from $\Phi_{\mathrm{fl}}$ and $\tau$ are listed in Table 3. The lifetimes measured in PMMA are of the same order of magnitude.

The temperature dependence of the fluorescence lifetime of $\mathbf{1}$ and $\mathbf{5}$ down to $77 \mathrm{~K}$ was also investigated by TCSPC in $\mathrm{MeOH}$ and $\mathrm{MCH}$. The observed temperature dependence of the
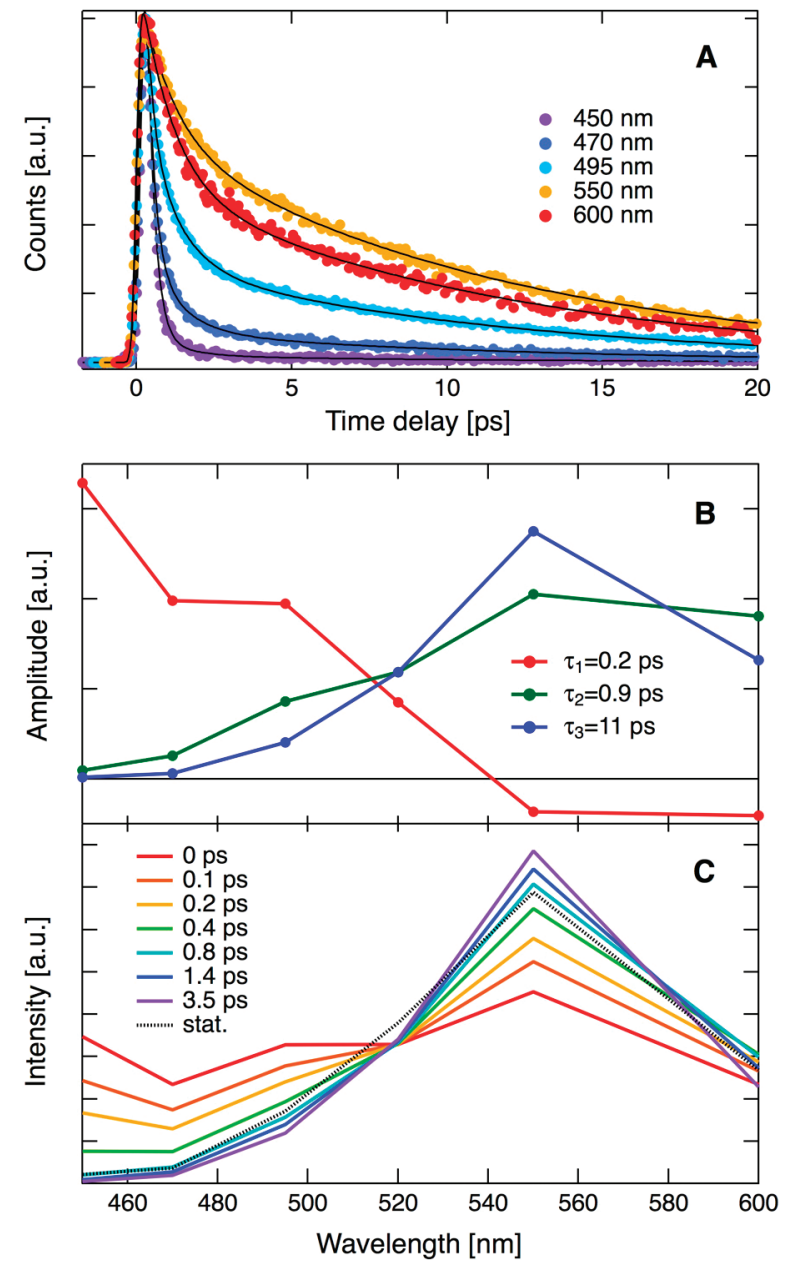

Figure 4. (A) Fluorescence time profiles of 5 in acetonitrile. (B) Decayassociated spectra obtained from the global analysis of the fluorescent dynamics of $\mathbf{5}$ in acetonitrile. (C) Reconstructed area-normalized timeresolved emission spectra and stationary spectrum (dotted).

TABLE 3: Fluorescence Lifetimes, $\tau$, and Radiative Time Constants, $\tau_{\mathrm{r}}$, of 1-5 in PMMA at $300 \mathrm{~K}$ and in Ethanol at $77 \mathrm{~K}$

\begin{tabular}{ccccr}
\hline & PMMA $(300 \mathrm{~K})$ & & \multicolumn{2}{c}{ ethanol $(77 \mathrm{~K})$} \\
\cline { 2 - 2 } & & & $\tau(\mathrm{ns})$ & $\tau_{\mathrm{r}}(\mathrm{ns})$ \\
\hline $\mathbf{1}$ & 2.9 & & 3.4 & 3.4 \\
$\mathbf{2}$ & 1.7 & & 2.5 & 12.5 \\
$\mathbf{3}$ & 1.9 & & 2.3 & 7.7 \\
$\mathbf{4}$ & $a$ & & 2.8 & 14.0 \\
$\mathbf{5}$ & 1.8 & 2.9 & 9.7 \\
${ }^{a}$ Measurement not performed. & &
\end{tabular}

nonradiative rate constant, calculated as $k_{\mathrm{nr}}=\tau^{-1}-\tau_{\mathrm{r}}^{-1}$ and assuming $\tau_{\mathrm{r}}$ independent of temperature, clearly departs from an Arrhenius behavior, with a marked kink around $130 \mathrm{~K}$ (Figure S3 in Supporting Information). Such an effect, already reported for other GFP fluorophores ${ }^{15}$ as well as for Malachite Green, ${ }^{93}$ reflects a change in the nature of the matrix occurring above the glass transition temperature and can be considered as a strong indication of the involvement of intramolecular modes with large amplitude motion in the nonradiative deactivation of $\mathbf{1}$ and $\mathbf{5}$.

Transient Absorption Measurements. To have a deeper insight into the excited-state dynamics of these compounds, TA measurements have been performed with $\mathbf{1 - 5}$ in $\mathrm{ACN}, \mathrm{EtOH}$, and $\mathrm{CH}$. Figure 5A shows TA spectra recorded with 3 in ACN 


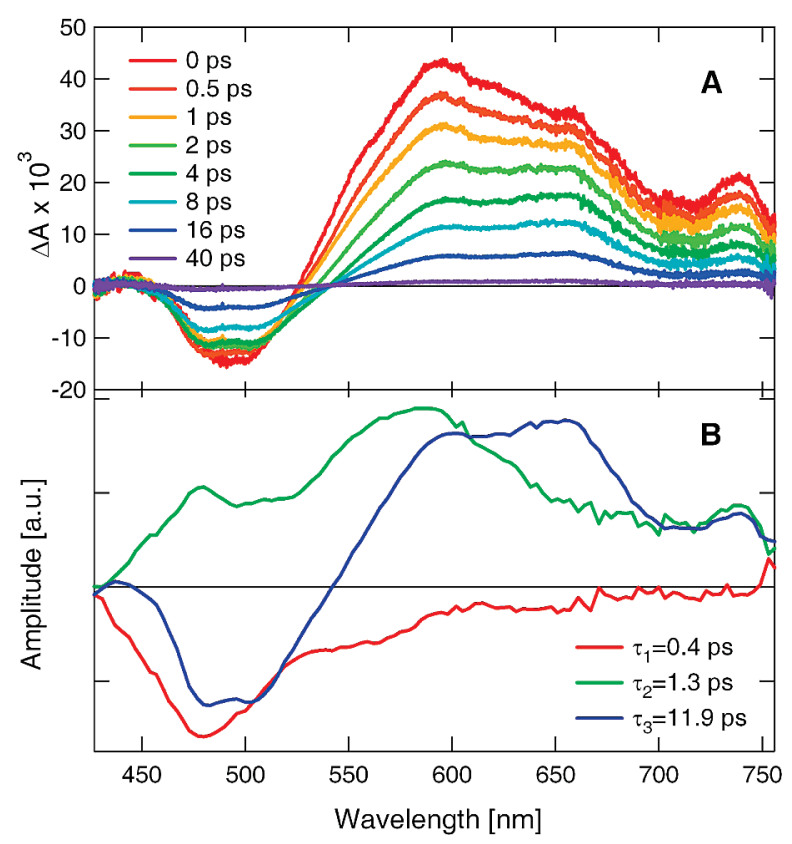

Figure 5. (A) TA spectra recorded with $\mathbf{3}$ in acetonitrile at different time delays after excitation. (B) Decay-associated spectra obtained from multiexponential global analysis.

at different time delays after $400 \mathrm{~nm}$ excitation. The spectra consist of a negative band located between 470 and about 530 $\mathrm{nm}$, which can be ascribed to $\mathrm{S}_{1}-\mathrm{S}_{0}$ stimulated emission (SE) and of a broad positive band above $530 \mathrm{~nm}$ that can be assigned to $\mathrm{S}_{1}$ excited-state absorption (ESA). Comparison of the negative SE band with the spontaneous fluorescence spectrum, which extends from 470 to $650 \mathrm{~nm}$, points to a substantial overlap of SE and ESA spectra. As time proceeds, the intensity of both bands exhibits a parallel decay to zero. A closer inspection of the SE band allows some small changes of the shape with time to be observed, especially a broadening of the red edge. Similarly, the ESA band shape presents some temporal variation. At early time, its maximum is located at about $600 \mathrm{~nm}$ with a secondary maximum around $650 \mathrm{~nm}$. About 2-3 ps after excitation, the intensity at both wavelengths is identical and, at later time, the main ESA maximum is at $650 \mathrm{~nm}$. The decay of the TA intensity over the whole spectral window can be well reproduced with the sum of three exponential functions with $0.4,1.3$, and 11.9 ps time constants and with the decayassociated spectra shown in Figure 5B. It appears that most of the dynamics in the ESA region can be well accounted for with the two slower components. The distinct decay-associated spectra of these two components explain the temporal variation of the ESA band shape. On the other hand, the 0.4 ps component is required to reproduce the early spectral dynamics in the SE band region. Given this very short time constant, the amplitude of its associated spectrum might be overestimated relative to that of the other two decay associated spectra. The three time constants are in good agreement with those obtained from the analysis of the fluorescence up-conversion data (Tables 2 and 4).

No significant difference can be observed in EtOH, apart from the time constants, which are very close to those found in the fluorescence measurements as well (Tables 2 and 4). In $\mathrm{CH}$, the TA spectra are also quite similar except for the ESA band, which extends to longer wavelengths (Figure S3 in Supporting Information). In this case again, a very good agreement of TA and up-conversion time constants is obtained.
TABLE 4: Time Constants Obtained from a Multiexponential Global Analysis of the Transient Absorption Spectra

\begin{tabular}{cllcr}
\hline & solvent & $\tau_{1}(\mathrm{ps})$ & $\tau_{2}(\mathrm{ps})$ & $\tau_{3}(\mathrm{ps})$ \\
\hline $\mathbf{1}$ & acetonitrile & 0.4 & 1.0 & 22.7 \\
& ethanol & 0.2 & 1.2 & 16.8 \\
$\mathbf{2}$ & cyclohexane & 0.6 & 3.1 & 114.0 \\
& acetonitrile & 0.4 & 1.2 & $\mathbf{1 1 . 9}$ \\
& ethanol & 0.7 & 2.6 & $\mathbf{9 . 4}$ \\
$\mathbf{3}$ & cyclohexane & $<\mathrm{IRF}$ & 0.9 & 11.1 \\
& acetonitrile & 0.4 & 1.3 & 11.9 \\
& ethanol & 0.3 & 1.7 & 12.1 \\
$\mathbf{4}$ & cyclohexane & 1.3 & 8.9 & 122 \\
& acetonitrile & 0.4 & 1.2 & 11.9 \\
& ethanol & 0.5 & 2.8 & 13.6 \\
$\mathbf{5}$ & cyclohexane & 0.4 & 7.1 & $\mathbf{1 0 6 . 8}$ \\
& acetonitrile & 0.2 & 0.9 & 11.0 \\
& ethanol & 0.2 & 1.5 & 8.3 \\
& cyclohexane & 0.1 & 1.1 & 11.4
\end{tabular}

The TA spectra measured with $\mathbf{1}$ and $\mathbf{4}$ in all three solvents are qualitatively very similar to those of $\mathbf{3}$. With $\mathbf{2}$ on the other hand, the ESA band shape remains essentially unchanged over the whole excited-state lifetime.

A quite different behavior was observed with $\mathbf{5}$ in polar solvents as illustrated in Figure 6A. The very early TA spectra consist in two negative bands, one around $450 \mathrm{~nm}$ and the other around $540 \mathrm{~nm}$, and in two positive bands, one at $500 \mathrm{~nm}$ and the other above $570 \mathrm{~nm}$. The shortest wavelength band can be safely ascribed to the bleach of the $\mathrm{S}_{0}-\mathrm{S}_{1}$ absorption, whereas the other one arises from $S_{1}-S_{0} S E$. Over a few hundreds of femtoseconds, the SE band shifts to the red. As time proceeds, the intensity of the long wavelength positive band decreases, whereas the TA intensity around $500 \mathrm{~nm}$ increases to reach its maximum at about $1.1 \mathrm{ps}$. Then the TA intensity over the whole spectral window decreases, and after about $50 \mathrm{ps,} \mathrm{the} \mathrm{TA}$ spectrum remains unchanged until $1.8 \mathrm{~ns}$, the maximum time delay of the experiment.

As shown in Figure 6C, the time profile of the intensity of the two positive TA bands suggests a precursor-successor relationship of the populations responsible for these two bands. To confirm the existence of such relationship, a global fit with target analysis was performed assuming an $\mathrm{A} \rightarrow \mathrm{B} \rightarrow \mathrm{C}$ reaction scheme, where both $\mathrm{A} \rightarrow \mathrm{B}$ and $\mathrm{B} \rightarrow \mathrm{C}$ steps follow a firstorder kinetics. The overall decay of the TA spectra was well reproduced with this model, but strong deviation was observed during the first $2 \mathrm{ps}$, as the initial rise could not be well accounted for. However, much better agreement over the whole time window was obtained upon addition of a third step to the model, namely, assuming an $\mathrm{A} \rightarrow \mathrm{B} \rightarrow \mathrm{C} \rightarrow \mathrm{D}$ reaction scheme. The time constants for the three consecutive steps amount to $0.3,0.9$, and $11.8 \mathrm{ps}$, and the spectra of the four species A, B, $\mathrm{C}$, and D are shown in Figure 6B. All A, B, and C spectra exhibit a negative band below $490 \mathrm{~nm}$ due to the ground-state depletion. A second negative band arising from SE is also present in all spectra; however that of A peaks at $530 \mathrm{~nm}$, whereas those of $B$ and $C$ are centered at $550 \mathrm{~nm}$. The species $\mathrm{D}$ accounts for the very small residual TA spectrum measured after about $50 \mathrm{ps}$. These findings agree very well with the fluorescence up-conversion data that point to a conversion between two emitting species with distinct spectra. The similarity of the spectra associated with B and C suggests that these two species are closely related, whereas that of A has a different nature.

A qualitatively similar behavior was observed in EtOH. However, the intensity of the $500 \mathrm{~nm}$ band is relatively smaller 

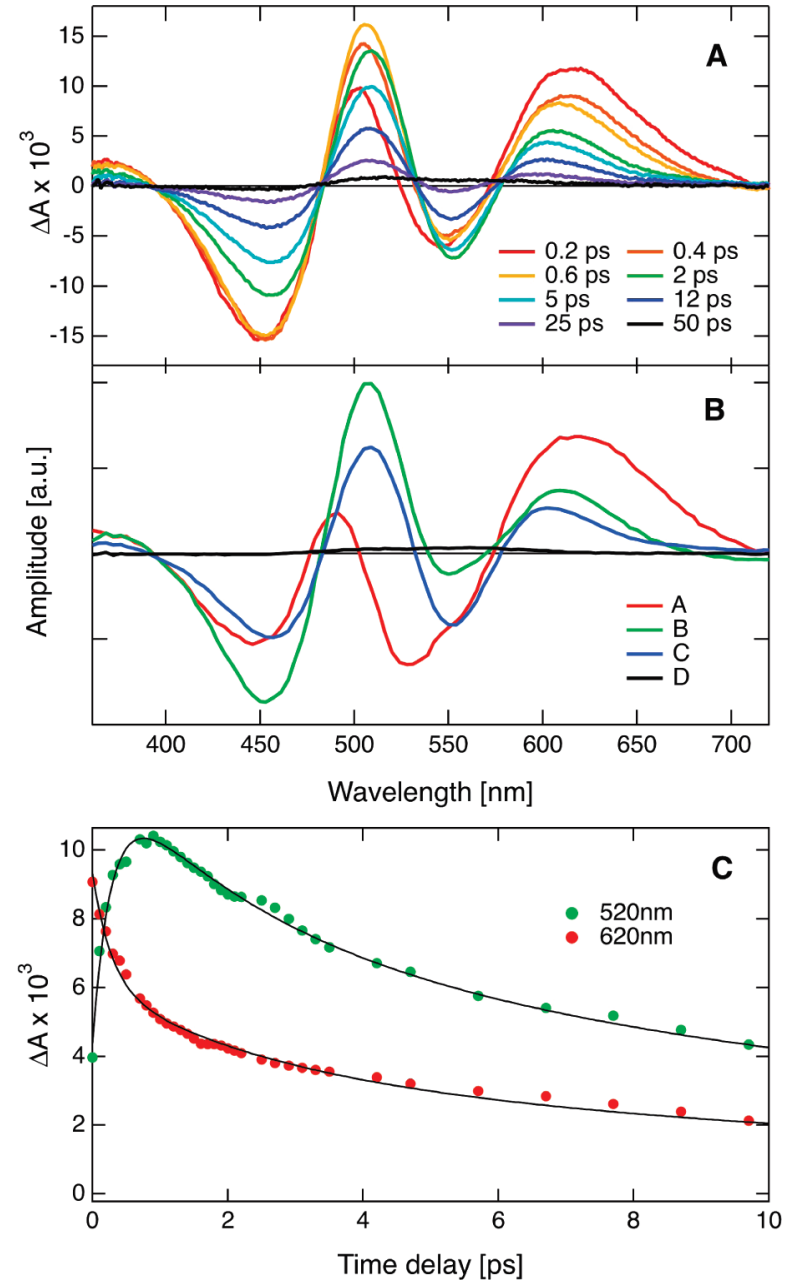

Figure 6. (A) TA spectra recorded with $\mathbf{5}$ in acetonitrile at different time delays after excitation. (B) Species-associated spectra obtained from target analysis assuming a $\mathrm{A} \rightarrow \mathrm{B} \rightarrow \mathrm{C} \rightarrow \mathrm{D}$ scheme. (C) TA profiles at the maximum of the two positive bands and best biexponential global fit.

than that in ACN. Performing the same analysis as in ACN resulted in a good agreement with the data as well, with $\tau_{\mathrm{AB}}=$ $0.3 \mathrm{ps}, \tau_{\mathrm{BC}}=1.5 \mathrm{ps}$ and $\tau_{\mathrm{CD}}=7.9 \mathrm{ps}$ for the $\mathrm{A} \rightarrow \mathrm{B}, \mathrm{B} \rightarrow \mathrm{C}$, and $\mathrm{C} \rightarrow \mathrm{D}$ steps, respectively. In EtOH, the $\tau_{\mathrm{CD}} / \tau_{\mathrm{BC}}$ ratio amounts to about 5, whereas it is as large as 13 in ACN. This means that in $\mathrm{EtOH}$, the population of species $\mathrm{C}$ does not accumulate as much as that in ACN, explaining the smaller relative intensity of the $500 \mathrm{~nm}$ TA band.

Finally, the TA spectra of $\mathbf{5}$ in $\mathrm{CH}$ differ substantially from those in polar solvents (Figure 7) and resemble rather those measured with 1-4. Apart from spectral changes occurring at very early time and most probably associated with vibrational relaxation, the shape of the ESA band remains constant over the lifetime of the excited state.

The time constants obtained from the multiexponential global analysis of the TA spectra of compounds $\mathbf{1}$ to $\mathbf{5}$ are summarized in Table 4. It can be seen that in all cases, these time constants match very well with those extracted from the fluorescence upconversion data. In fact, global analysis of both the fluorescence and TA data could also be performed successfully and yielded time constants between those obtained upon separate analysis of the fluorescence and TA data. However, the components with the time constants written in bold characters in Table 4 are not present in the fluorescence data. These values, which always correspond to the slowest components, can be assigned to

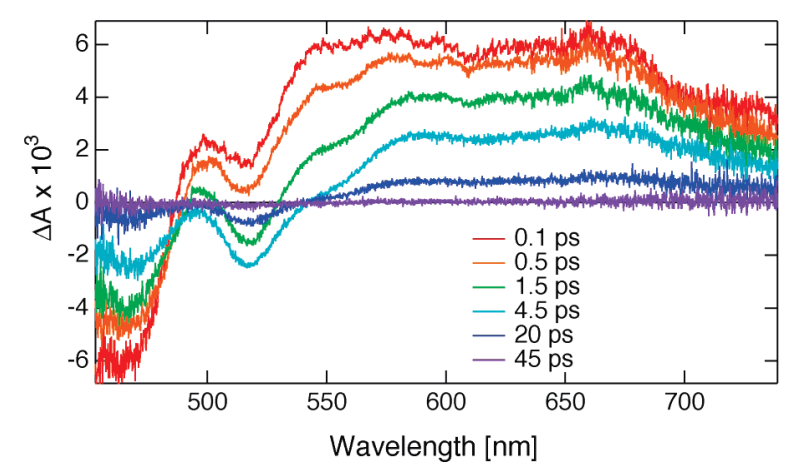

Figure 7. TA spectra recorded with $\mathbf{5}$ in cyclohexane at different time delays after excitation.

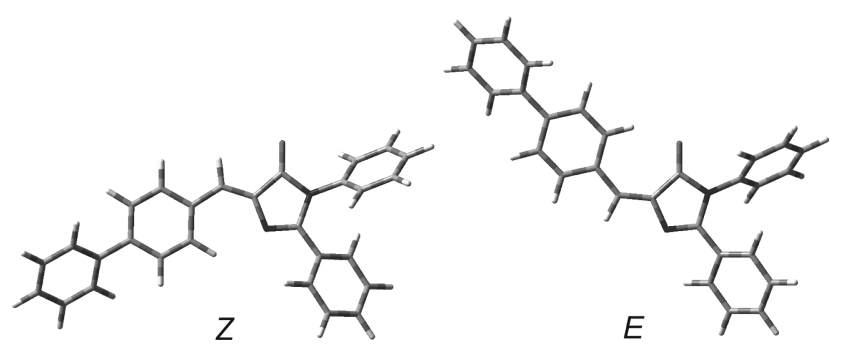

Figure 8. Optimized ground-state geometries of $Z$ and $E$ isomers of 3 calculated at the B3LYP level of theory.

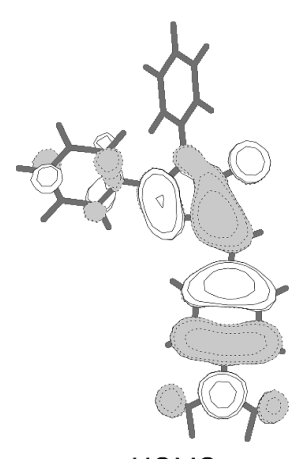

$\mathrm{HOMO}$

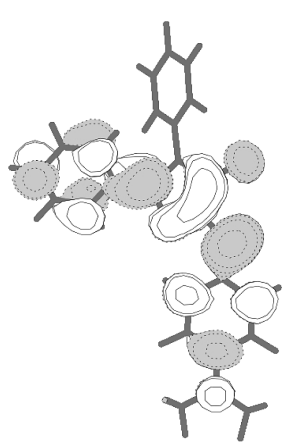

LUMO
Figure 9. Frontier molecular orbitals of $\mathbf{5}$ computed at the B3LYP level of theory. The orbital contours are drawn at the 0.02 au level.

nonemitting species. For $\mathbf{2}$ and 4, their decay-associated spectra are quite similar to that related to the 12 ps time constant shown in Figure 5B. In the case of $\mathbf{5}$, this long-lived component is associated with species D in Figure 6B. As it can be seen, the amplitude of the associated spectrum is very small. Thus, species $\mathrm{D}$ is most probably the ground state of $\mathbf{5}$ and the small associated spectrum might originate from some photoproduct.

Quantum Chemistry Calculations. The ground-state calculations predict the presence of two stable forms for all compounds (Figure 8), except for $\mathbf{2}$ where no convergence could be achieved for the $E$ form. Comparison of the total energies of the $Z$ and $E$ forms of $\mathbf{1 ,} \mathbf{3}$, and $\mathbf{5}$ shows that the $Z$ isomer is more stable by about $3 \mathrm{kcal} / \mathrm{mol}$. For 4 on the other hand, the $E$ isomer is more stable than the $Z$ form.

According to the TDDFT calculations, the $\mathrm{S}_{0}-\mathrm{S}_{1}$ absorption band of $\mathbf{5}$ is essentially connected to a one-electron HOMOLUMO transition and has a $\pi \pi^{*}$ character. The pronounced bathochromic shift of both absorption and fluorescence bands of 5 points to $\pi \pi^{*}$ transition with some charge transfer (CT) character as testified by the HOMO and LUMO shown in Figure 9. Thus optical excitation of $\mathbf{5}$ leads to a substantial charge redistribution from the $\mathrm{Ar}^{1}$ substituent to one of the phenyl groups on the imidazolone moiety. 


\section{Discussion}

Multiexponential Excited-State Dynamics. The fluorescence dynamics of all five compounds in liquid solution is clearly multiexponential. Whereas the fastest dynamic components can be safely ascribed to solvent and/or to vibrational relaxation, the remaining components can be assigned to the decay of excited-state populations with slightly different fluorescence spectra.

This interpretation is corroborated by the TA measurements, where a marked temporal variation of the ESA spectrum is observed (Figure 5). The time scale of this spectral dynamics is very similar to that found by fluorescence. Moreover, the decay-associated spectra obtained from global analysis of the TA spectra point to excited-state populations with slightly different absorption spectra as well.

Multiexponential fluorescence decay has already been observed with other derivatives of the GFP chromophore ${ }^{14-16}$ and was attributed to the existence of several ground-state conformations. The same interpretation can be proposed here for $\mathbf{1 - 5}$. Considering the flexibility of these molecules, a distribution of ground-state conformers with different torsion angles around the single bonds between the imidazolone core and the two phenyl substituents as well as around the ethylenic bridge can be expected. Although the fluorescence and excited-state absorption spectra of these conformers differ slightly, their $\mathrm{S}_{0}-\mathrm{S}_{1}$ absorption band seems to be almost identical. Indeed, the fluorescence excitation spectra of $\mathbf{1 - 5}$ are independent of the emission wavelength. Furthermore, the fluorescence dynamics of 3 recorded by up-conversion upon 370 and $420 \mathrm{~nm}$ excitation are identical, within experimental error, to that measured upon $400 \mathrm{~nm}$ excitation.

On the other hand, the fluorescence decay of these compounds in solid matrices, namely, PMMA films and EtOH glasses at $77 \mathrm{~K}$, is single exponential. At $77 \mathrm{~K}$, this could be explained by a decrease of the torsional disorder at low temperature and thus by the existence of a single conformer. However, this interpretation cannot account for the single exponential fluorescence decay in room temperature PMMA films. Therefore, unless the polymeric environment imposes a well-defined ground-state structure of $\mathbf{1 - 5}$, a distribution of conformers should also be expected as in liquids. This implies that these conformers have essentially the same fluorescence lifetime in polymeric environments and consequently they have the same radiative time constant, $\tau_{\mathrm{r}}$, and the same nonradiative dynamics. Identical radiative time constants agree with the undistinguishable absorption spectra of these conformers. Thus, the multiexponential fluorescence decays in liquid solutions indicate that the conformers have different nonradiative dynamics in a nonrigid environment. The difference with solid matrices clearly shows that the nonradiative pathways in liquids should be associated with conformational dynamics. This will be discussed in more detail below.

Nonradiative Decay Pathways. When considering the structures of 1-5, several nonradiative deactivation pathways of the $S_{1}$ state can be envisaged: (i) IC by large amplitude motion for all of them, (ii) intermolecular H-bonded assisted deactivation for all of them in protic solvents, (iii) intramolecular H-bond assisted deactivation for $\mathbf{4}$, and (iv) intramolecular CT with $\mathbf{5}$.

(i) In principle, IC via large amplitude motion is the only radiationless decay pathway that can be operative with $\mathbf{1}$ and $\mathbf{3}$ in nonprotic solvents. Table 2 shows that the fluorescence time constants of $\mathbf{3}$ related to population dynamics, $\tau_{2}$ and $\tau_{3}$, increase with viscosity in the three nitriles investigated. The viscosity
TABLE 5: Viscosity, $\eta$, Static Dielectric Constant, $\varepsilon_{\mathrm{s}}$, and Kamlet-Taft Parameter, $\alpha$, of the Solvents Used

\begin{tabular}{llll}
\hline \multicolumn{1}{c}{ solvent } & $\eta^{a}(\mathrm{cP})$ & $\varepsilon_{\mathrm{s}}{ }^{a}$ & $\alpha^{d}$ \\
\hline$n$-hexane & 0.298 & 1.88 & 0 \\
cyclohexane & 0.90 & 2.02 & 0 \\
decaline & 2.42 & 2.15 & 0 \\
acetonitrile & $0.325^{b}$ & $37.5^{c}$ & 0.15 \\
proprionitrile & $0.39^{b}$ & $27.2^{c}$ & 0 \\
butyronitrile & $0.515^{b}$ & $20.3^{c}$ & 0 \\
methanol & 0.54 & 32.7 & 0.98 \\
ethanol & 1.08 & 24.55 & 0.86 \\
pentanol & 3.35 & 13.9 & 0.84
\end{tabular}

${ }^{a}$ From ref 94 , if not specified at $25^{\circ} \mathrm{C} .{ }^{b}$ At $30{ }^{\circ} \mathrm{C}$. ${ }^{c}$ At $20{ }^{\circ} \mathrm{C}$. ${ }^{d}$ From ref 95.

dependence of IC via large amplitude motion is often discussed in terms of the following empirical relationship: ${ }^{96}$

$$
\tau_{\mathrm{nr}} \propto \eta^{\alpha}
$$

where $\eta$ is the solvent viscosity and $\alpha$ is a factor varying between 0.1 and $1, \alpha=1$ corresponding to the high friction limit in Kramers theory. ${ }^{97}$ This relationship has been rationalized by Grote and Hynes in terms of frequency-dependent friction. ${ }^{98}$

Although eq 2 cannot be used very reliably with only three solvents, doubly logarithmic plots of $\tau_{2}$ and $\tau_{3}$ vs $\eta$ yield $\alpha$ values of 0.6 and 1.5, respectively. Despite the large errors on these two values, the faster decay component is clearly less viscosity dependent than the slower one. This is in good agreement with the assignment of these time constants to different excited conformers. Thus, the motion responsible for the nonradiative deactivation of the conformers does not experience the same friction from the environment. Most probably, the conformers with $\tau_{3}$ has to undergo larger amplitude motion than the shorter lived ones, i.e., those with $\tau_{2}$.

The barrier height for photoisomerization and IC via large amplitude motion may also depend on the solvent polarity, if the electronic distribution of the transition state differs from that of the initial state. ${ }^{99,100}$ For example, if the transition state is more polar, the reaction rate increases with solvent polarity. This is probably the case for $\mathbf{1}$ and $\mathbf{3}$, for which the fluorescence time constants are clearly larger in nonpolar solvents, independently of their viscosity. Consequently, the very large $\alpha$ values most probably do not only reflect friction effects but also the decrease of polarity that accompanies the increase of viscosity when going from $\mathrm{ACN}$ to $\mathrm{BuCN}$. A reliable determination of $\alpha$ would require a series of solvents with the same polarity but with different viscosity.

(ii) Intermolecular hydrogen bond formation has been shown to substantially accelerate the excited-state decay of chromophores with carbonyl groups. ${ }^{101-104}$ This interaction can be viewed as an excited-state proton transfer leading to an unstable product, which in turn decays to the ground state by back proton transfer. To see whether such a process is also operative with $\mathbf{1 - 5}$, the excited-state dynamics of $\mathbf{1}$ and $\mathbf{2}$ should be compared in protic and aprotic solvents of similar viscosity and dielectric constant, $\varepsilon_{\mathrm{s}}$ (see Table 5). For example, the average excitedstate lifetime of $\mathbf{3}$ is markedly shorter in $\mathrm{MeOH}$ than in $\mathrm{PrCN}$ and is also shorter in $\mathrm{EtOH}$ than in $\mathrm{BuCN}$ (Table 2). Similarly, the excited-state lifetimes of the other compounds in $\mathrm{EtOH}$ are at least as short as those in $\mathrm{ACN}$, although EtOH is substantially more viscous and less polar than ACN (Table 5). Therefore, the shorter lifetime of $\mathbf{1 - 5}$ in protic solvents can be rather safely ascribed to H-bond-assisted nonradiative deactivation occurring additionally to IC by large amplitude motion. The shortening 
of the excited-state lifetime observed by going from $\mathrm{MeOH}$ to $\mathrm{PeOH}$ can be explained by both the decrease of the hydrogenbonding ability of the solvent, quantified by the Kamlet-Taft parameter $\alpha$ (Table 5), and the increase of viscosity, that slows down large amplitude motion.

The hydroxyl group in $\mathrm{Ar}^{1}$ in $\mathbf{2}$ could also be involved in $\mathrm{H}$-bonds with the solvent. Comparison of $\mathbf{2}$ with $\mathbf{1}$ and $\mathbf{3}$ also points to a faster nonradiative deactivation of the excited-state lifetime of 2. However, this difference is also present in $\mathrm{CH}$, which has no H-bond acceptance property, and thus the observed acceleration of the nonradiative decay of $\mathbf{2}$ could be due to another effect, like for example a decrease of the barrier height for large amplitude motion around the ethylenic bond induced by the presence of the electron-donating $\mathrm{OH}$ group. Indeed, the position of the $\mathrm{OH}$ group in HBDI, para or meta, was found to have a marked influence on the excited-state lifetime. ${ }^{32}$

(iii) Intramolecular H-bond interaction between the hydroxyl group on the $\mathrm{Ar}^{2}$ ring and the carbonyl oxygen is in principle also possible in 4 . The effect of this $\mathrm{OH}$ group can be evaluated by comparing the excited-state dynamics of $\mathbf{4}$ and $\mathbf{3}$ (Tables 2 and 4). Whereas no significant difference can be observed in polar solvents, substantially shorter fluorescence lifetime can be seen for $\mathbf{4}$ in nonpolar solvents, with an about 10 times shorter average lifetime. This effect is also reflected by the smaller fluorescence quantum yield of $\mathbf{4}$ in $\mathrm{CH}$ (Table 1). These results point to the existence of an intramolecular $\mathrm{H}$-bond in nonpolar media, favoring the nonradiative deactivation of the excited state. The absence of a difference between $\mathbf{4}$ and $\mathbf{3}$ in polar solvents could be explained by a twist of the phenol substituent relative to the imidazolone ring, inhibiting intramolecular H-bonding. Competition between inter- and intramolecular H-bonding could also explain the very similar fluorescence lifetimes of $\mathbf{4}$ and $\mathbf{3}$ in protic solvents. Such competing H-bonding has recently been reported for naphthalenediimide derivatives. ${ }^{105}$

(iv) Whereas in nonpolar solvents, the photophysics of $\mathbf{5}$ resembles that of $\mathbf{1}$ and $\mathbf{3}$, distinct excited-state dynamics is observed with this compound in polar solvents. The solvatochromism of the first absorption band and of the fluorescence spectrum is indicative of a substantially larger electric dipole moment in the excited state than in the ground state of $\mathbf{5}$. Moreover, the large change of the emission band shape with solvent polarity (Figure 2) points to a different nature of the emitting state, a locally excited state (LE) in nonpolar solvents, and a CT state in polar solvents. According to the quantum chemistry calculations (Figure 9), the LE state should already possesses a non-negligible CT character. However, the CT state should be characterized by a further degree of charge separation, most probably favored by solvation and by structural rearrangement of the excited-state, as is often the case in flexible molecules undergoing intramolecular CT. ${ }^{106-108}$ Therefore, the reconstructed time-resolved fluorescence spectra of $\mathbf{5}$ in $\mathrm{ACN}$ (Figure 4C) can be interpreted as a transition from the LE to the CT state, rather than as a simple dynamic Stokes shift. This assignment is further reinforced by the TA dynamics (Figure 6) that could be very well reproduced assuming an $\mathrm{A} \rightarrow \mathrm{B} \rightarrow$ $\mathrm{C} \rightarrow \mathrm{D}$ reaction scheme with $\tau_{\mathrm{AB}}=0.3 \mathrm{ps}, \tau_{\mathrm{BC}}=0.9 \mathrm{ps}$, and $\tau_{\mathrm{CD}}=11.8 \mathrm{ps}$ time constants in ACN. The strong similarity of the spectra associated with species $\mathrm{B}$ and $\mathrm{C}$ suggests that $\mathrm{A}$ is the LE state, B is a nonequilibrated CT state, C is the relaxed CT state, and D is the ground state. In most cases, the fluorescence lifetime of intramolecular CT states is on the nanosecond time scale. ${ }^{106,109-111}$ As a consequence, the very fast decay of the CT state found here with $\mathbf{5}$ is also most probably due to IC via large amplitude motion, like in $\mathbf{1 - 4}$, rather than to the charge recombination of the CT state. The excited-state dynamics of $\mathbf{5}$ and of other imidazolone derivatives undergoing similar intramolecular CT will be discussed in more detail elsewhere.

Comparison with $\boldsymbol{p}$-HBDI. $p$-HBDI is probably the most studied model of the GFP chromophore. Its structure is essentially the same as that of $\mathbf{2}$ except that $\mathrm{Ar}^{2}$ and the phenyl substituent in position 7 are methyl groups. Therefore, the excited-state dynamics of both $p$-HBDI and 2 can be expected to be very similar. The fluorescence decay of $p$-HBDI in a series of alcohols ranging from $\mathrm{MeOH}$ to decanol has been reported to be biexponential with time constants around $200 \mathrm{fs}$ and 1 ps, independently on the solvent viscosity. ${ }^{16}$ As shown in Table 2, the decay times found with 2 in $\mathrm{ACN}$ and $\mathrm{MeOH}$ do not differ very much, confirming similar deactivation pathways of $p$-HBDI and 2 . Therefore by analogy with 2 , it appears that, depending on the solvent, the deactivation pathways of $p$-HBDI should be IC by large amplitude motion and intermolecular $\mathrm{H}$-bond assisted deactivation. The number of solvents investigated with $\mathbf{2}$ does not allow conclusions on the relative efficiency of both channels to be drawn. However, the very weak viscosity dependence reported for $p$-HBDI by Mandal et al. ${ }^{16}$ in alcohols could be explained by the predominance of H-bond-assisted deactivation. This is in full agreement with the recent study of Yang et al., who found that the photoisomerisation yield of $p$-HBDI is much smaller in protic than in aprotic solvents. ${ }^{25}$ Our study clearly shows that H-bonding to the imidazolinone group is involved in the deactivation. The shorter excited-state lifetime found with $\mathbf{2}$ compared to $\mathbf{1}$ and $\mathbf{3}$ suggests that $\mathrm{H}$-bonding between the hydroxy group and solvent molecules is also probably operative. Further investigation of the solvent dependence of the excited-state dynamics of $\mathbf{2}$ is in progress.

\section{Conclusion}

The results presented here clearly show that some tuning of the excited-state dynamics of GFP-chromophores can be achieved beyond the simple variation of the medium rigidity. For the compounds investigated here in liquid solutions, IC by large amplitude motion is an important radiationless channel of the excited state. Nevertheless, additional pathways can be opened, such as inter- and intramolecular H-bond-assisted deactivation, depending on the solvent and the substituent. Occurrence of these processes further reduces the excited-state lifetime of these chromophores. These results give a deeper insight into the ultrafast nonradiative deactivation of $p$-HBDI, the most investigated GFP chromophore model, as its structure is very similar to those of the compounds studied here.

Furthermore, the nature of the excited state can be substantially changed by introducing strong electron-donating substituents. This combination of viscosity dependence of the fluorescence quantum yield together with the polarity dependence of the emission wavelength is not so common and therefore these GFP-chromophores derivatives with CT character may find potential applications as local molecular probes. Finally, controlling the CT character of the excited state of these molecules should in principle allow a rather fine-tuning of their emission wavelength even in rigid media, where their emission quantum yield is very large. These compounds may thus also be potential candidates as fluorophores in electroluminescent devices.

Acknowledgment. The authors would like to thank K.M. Solntsev for fruitful discussions. I.P. acknowledges financial support from NATO Security Through Science Programme (RIG 
ref. No. 9811325) and European Science Foundation (DYNA Exchange Grant 1893). This work was supported by Swiss National Science Foundation (grant No. 200020-115942).

Supporting Information Available: Synthesis of 1-5, fluorescence decay of $\mathbf{2}$ in a PMMA film, temperature dependence of the nonradiative rate constants of $\mathbf{1}$ and $\mathbf{5}$ in $\mathrm{MeOH}$ and $\mathrm{MCH}$, and TA spectra recorded with $\mathbf{3}$ in $\mathrm{CH}$. This information is available free of charge via the Internet at http:// pubs.acs.org.

\section{References and Notes}

(1) Zimmer, M. Chem. Rev. 2002, 102, 3-759.

(2) Misteli, T.; Spector, D. L. Nat. Biotechnol. 1997, 15, 10-961.

(3) Cubbit, A. B.; Heim, R.; Adams, S. R.; Boyd, A. E.; Gross, L. A.; Tsien, R. Y. Trends Biochem. Sci. 1995, 20, 448.

(4) Prendergast, F. G. Methods Cell Biol. 1999, 58, 1.

(5) Tsien, R. Y. Аnпи. Rev. Biochem. 1998, 67, 509.

(6) Chattoraj, M.; King, B. A.; Bublitz, G. U.; Boxer, S. G. Proc. Natl. Acad. Sci. U.S.A. 1996, 93, 8362.

(7) Heim, R.; Prasher, D. C.; Tsien, R. Y. Proc. Natl. Acad. Sci. U.S.A. 1994, $91,12501$.

(8) Lossau, H.; Kummer, A.; Heinecke, R.; Poellinger-Dammer, F.; Kompa, C.; Bieser, G.; Jonsson, T.; Silva, C. M.; Yang, M. M.; Youvan, D. C.; Michel-Beyerle, M. E. Chem. Phys. 1996, 213, 1.

(9) Cubbit, A. B.; Woolenweber, L. A.; Heim, R. Methods Cell Biol. 1999, $58,19$.

(10) Perozzo, M. A.; Ward, K. B.; Thompson, R. B.; Ward, W. W. J. Biol. Chem. 1988, 263, 7713 .

(11) Niwa, H.; Inouye, S.; Hirano, T.; Matsuno, T.; Kojima, S.; Kubota, M.; Ohashi, M.; Tsuji, F. I. Proc. Natl. Acad. Sci. U.S.A. 1996, 93, 13617. (12) Cody, C. W.; Prasher, D. C.; Westler, W. M.; Prendergast, F. G.; Ward, W. W. Biochemistry 1993, 32, 1212.

(13) Webber, N. M.; Litvinenko, K. L.; Meech, S. R. J. Phys. Chem. B 2001, 105, 8036 .

(14) Mandal, D.; Tahara, T.; Webber, N. M.; Meech, S. R. Chem. Phys. Lett. 2002, 358, 495 .

(15) Litvivenko, K. L.; Webber, N. M.; Meech, S. R. J. Phys. Chem. A 2003, 107, 2616

(16) Mandal, D.; Tahara, T.; Meech, S. R. J. Phys. Chem. B 2004, 108,1102 $6,976$.

(17) Webber, N. M.; Meech, S. R. Photochem. Photobiol. Sci. 2007,

(18) Altoe, P.; Bernardi, F.; Garavelli, M.; Orlandi, G.; Negri, F. J. Am. Chem. Soc. 2005, 127, 3952.

(19) Usman, A.; Mohammed, O. F.; Nibbering, E. T. J.; Dong, J.; Solntsev, K. M.; Tolbert, L. M. J. Am. Chem. Soc. 2005, 127, 11214.

(20) Martin, M. E.; Negri, F.; Olivucci, M. J. Am. Chem. Soc. 2004, 126,5452

(21) Stavrov, S. S.; Solntsev, K. M.; Tolbert, L. M.; Huppert, D. J. Am. Chem. Soc. 2006, 128, 1540.

(22) Voityuk, A. A.; Kummer, A. D.; Michel-Beyerle, M. E.; Rosch, N. Chem. Phys. 2001, 269, 83.

(23) Dong, J.; Abulwerdi, F.; Baldridge, A.; Kowalik, J.; Solntsev, K. M.; Tolbert, L. M. J. Am. Chem. Soc. 2008, 130, 14096.

(24) Dong, J.; Solntsev, K. M.; Tolbert, L. M. J. Am. Chem. Soc. 2009, 131,662 .

(25) Yang, J.-S.; Huang, G.-J.; Liu, Y.-H.; Peng, S.-M. Chem. Commun. 2008, 1344.

(26) Gepshtein, R.; Huppert, D.; Agmon, N. J. Phys. Chem. B 2006, 110,4434

(27) Follenius-Wund, A.; Bourotte, M.; Schmitt, M.; Iyice, F.; Lami, H.; Bourguignon, J.-J.; Haiech, J.; Pigault, C. Biophys. J. 2003, 85, 1839

(28) Bourotte, M.; Schmitt, M.; Follenius-Wund, A.; Pigault, C.; Haiech, J.; Bourguignon, J.-J. Tetrahedron Lett. 2004, 45, 6343.

(29) Kummer, A. D.; Kompa, C.; Niwa, H.; Hirano, T.; Kojima, S.; Michel-Beyerle, M. E. J. Phys. Chem. B 2002, 106, 7554.

(30) Chen, K.-Y.; Cheng, Y.-M.; Lai, C.-H.; Hsu, C.-C.; Ho, M.-L.; Lee, G.-H.; Chou, P.-T. J. Am. Chem. Soc. 2007, 129, 4534.

(31) Dong, J.; Solntsev, K. M.; Poizat, O.; Tolbert, L. M. J. Am. Chem. Soc. 2007, 129, 10084.

(32) Solntsev, K. M.; Poizat, O.; Dong, J.; Rehault, J.; Lou, Y.; Burda, C.; Tolbert, L. M. J. Phys. Chem. B 2008, 112, 2700.

(33) Weber, W.; Helms, V.; McCammon, J. A.; Langhoff, P. W. Proc. Natl. Acad. Sci. U.S.A. 1999, 96, 6177.

(34) Vengris, M.; van Stokkum, I. H. M.; He, X.; Bell, A. F.; Tonge, P. T.; van Grondelle, R.; Larsen, D. S. J. Phys. Chem. A 2004, 108, 4587. 439
(36) Manring, L.; Peters, K. S. J. Phys. Chem. 1984, 88, 3516.

(37) Hicks, J.; Vandersall, M.; Babarogic, Z.; Eisenthal, K. B. Chem. Phys. Lett. 1985, 116, 18.

(38) He, X.; Bell, A. F.; Tonge, P. J. FEBS Lett. 2003, 549, 35.

(39) Schellenberg, P.; Johnson, E.; Esposito, A. P.; Reid, P. J.; Parson,

W. W. J. Phys. Chem. B 2001, 105, 5316.

(40) You, Y.; He, Y.; Burrows, P. E.; Forrest, St. R.; Petasis, N. A.;

Thompson, M. E. Adv. Mater. 2000, 12 (22), 1678.

(41) Erlenmeyer, E. Ber. Dtsch. Chem. Ges. 1898, 31, 2239.

(42) Buck, J. S.; Ide, W. S. Organic Synthesis; Wiley: New York;

Collect. Vol. 2, 1943; p 55.

(43) Filler, R.; Rao, Y. S. Adv. Heterocycl. Chem. 1977, 21, 175.

(44) Carter, H. E. Org. React. 1974, 3, 198.

(45) Mukerjee, A. K.; Kumar, P. Heterocycles 1981, 16, 1995.

(46) Rao, Y. S.; Filler, R. Synthesis 1975, 12, 749.

(47) Kochetkov, N. P.; Budovskii, E. I.; Khomutov, R. M.; Karpeiskii, M. Y.; Severin, E. S. J. Gen. Chem., USSR (Engl. Transl.) 1960, 30, 2573.

(48) Brocklehurst, K.; Price, H. S.; Williamson, K. Chem. Commun. 1968, 884.

(49) Morgenstern, A. P.; Schuitj, C.; Nauta, W. T. Chem. Commun. 1969, 321 .

(50) Brocklehurst, K.; Bywater, R. P.; Palmer, R. A.; Patrick, R. Chem. Commun. 1971, 632.

(51) Rao, Y. S. J. Org. Chem. 1976, 41, 722.

(52) Kóczán, G.; Csík, G.; Csámpai, A.; Balog, E.; Bôsze, S.; Sohár, P.; Hudecz, F. Tetrahedron 2001, 57, 4589.

(53) Harhash, A. H.; Kassab, N. A. L.; Elbanani, A. A. A. Indian J. Chem. 1971, 789 .

(54) Crawford, M.; Little, W. T. J. Chem. Soc. 1959, 729.

(55) Acheson, R. M.; Booth, D. A.; Brettle, R.; Harris, A. M. J. Chem.

Soc. 1960, 3457.

(56) Kumar, P.; Mishra, H. D.; Mukerjee, A. K. Synthesis 1980, 836.

(57) Tripathy, P. K.; Mukerjee, A. K. Synthesis 1984, 418.

(58) Tripathy, P. K.; Mukerjee, A. K. Synthesis 1985, 285.

(59) Rao, P. S.; Venkataratnam, R. V. Indian J. Chem. 1994, 33B, 984.

(60) Puterová, Z.; Sterk, H.; Krutošíková, A. Molecules 2004, 9, 11.

(61) Royo, S.; Jiménez, A. I.; Cativiela, C. Tetrahedron: Asymmetry 2006, 17, 2393. 2935.

62) Conway, P. A.; Devine, K.; Paradisi, F. Tetrahedron 2009, 65,

(63) Cativiela, C.; Chueca, J.; Garcia, J. I.; Melendez, E. Heterocycles 1984, 22, 2775.

(64) Abbass, I. M.; Mosselhi, M. A.; Abdallah, M. A.; Shawali, A. S. J. Chem. Res. 1995, (S), 190.

(65) Mukerjee, A. K.; Kumar, P. Can. J. Chem. 1982, 60, 317.

(66) Túroś, G.; Csámpai, A.; Czugler, M.; Wamhoff, H.; Sohár, P. J. Organomet. Chem. 2001, 634, 122.

(67) Badr, M. Z. A.; El-Sherief, H. A. H.; Tadros, M. E. Indian J. Chem. 1979, 18B, 240.

(68) Topuzyan, V. O.; Oganesyan, A. A.; Panosyan, G. A. Russ. J. Org. Chem. (Eng.) 2004, 40, 1644.

(69) Ashare, R.; Mukerjee, A. K. Indian J. Chem. 1986, 25B, 762.

(70) Sanjayan, G. J.; Mukerjee, A. K. Indian J. Chem. 1994, 33B, 76.

(71) Tripathy, P. K. Indian J. Heterocycl. Chem. 2004, 14, 77.

(72) Tripathy, K.; Mukerjee, A. K. Indian J. Chem. 1986, 25B, 765.

(73) Abdallah, M. A.; Zayed, M. E.; Shawali, A. S. Indian J. Chem.

2001, 40B, 187.

(74) Nikolov, P.; Fratev, F.; Mintchev, St. Z. Naturforsch. 1983, 38 (A), 200 .

(75) Reynolds, G. A.; Drexhage, K. H. Opt. Commun. 1975, 13, 222.

(76) Morandeira, A.; Fürstenberg, A.; Gumy, J.-C.; Vauthey, E. J. Phys. Chem. A 2003, 107, 5375.

(77) Morandeira, A.; Engeli, L.; Vauthey, E. J. Phys. Chem. A 2002, 106,4833 .

(78) Duvanel, G.; Banerji, N.; Vauthey, E. J. Phys. Chem. A 2007, 111,5361 .

(79) Banerji, N.; Duvanel, G.; Perez-Velasco, A.; Maity, S.; Sakai, N.; Matile, S.; Vauthey, E. J. Phys. Chem. A 2009, 113, 8202.

(80) Furche, F.; Ahlrichs, R. J. Chem. Phys. 2002, 117, 7433.

(81) Becke, D. J. Chem. Phys. 1993, 5648.

(82) Lee, C.; Yang, W.; Parr, R. G. Phys. Rev. B 1988, 37, 785.

(83) Schäfer, A.; Huber, C.; Ahlrichs, R. J. Chem. Phys. 1994, 100, 5829.

(84) Treutler, O.; Ahlrichs, R. J. Chem. Phys. 1995, 102, 346.

(85) Von Arnim, M.; Ahlrichs, R. J. Comput. Chem. 1998, 19, 1746. (86) Deglmann, P.; Furche, F.; Ahlrichs, R. Chem. Phys. Lett. 2002,

362,511

(87) Deglmann, P.; Furche, F. J. Chem. Phys. 2002, 9535.

(88) Fürstenberg, A.; Vauthey, E. J. Phys. Chem. B 2007, 111, 12610.

(89) Horng, M. L.; Gardecki, J. A.; Papazyan, A.; Maroncelli, M. J.

Phys. Chem. 1995, 99, 17311. 
(90) Pigliucci, A.; Duvanel, G.; Lawson Daku, M. L.; Vauthey, E. J. Phys. Chem. A 2007, 111, 6135.

(91) Siemiarczuk, A.; Wagner, B. D.; Ware, W. R. J. Phys. Chem. 1990, 94, 1661.

(92) Wlodarczyk, J.; Kierdaszuk, B. Biophys. J. 2003, 85, 589.

(93) Ye, J. Y.; Hattori, T.; Inouye, H.; Ueta, H.; Nakatsuka, H.; Maruyama, Y.; Ishikawa, M. Phys. Rev. B 1996, 53, 8439.

(94) Riddick J. A.; Bunger W. B. Organic Solvents; J. Wiley: New York, 1970.

(95) Marcus, Y. Chem. Soc. Rev. 1993, 22, 409-416.

(96) Velsko, S. P.; Fleming, G. R. Chem. Phys. 1982, 65, 59.

(97) Kramers, H. A. Physica (Utrecht) 1940, 7, 284.

(98) Grote, H. F.; Hynes, J. T. J. Chem. Phys. 1980, 73, 2715.

(99) Hicks, J. M.; Vandersall, M. T.; Sitzmann, E. V.; Eisenthal, K. B. Chem. Phys. Lett. 1987, 135, 413.

(100) Pigliucci, A.; Vauthey, E.; Rettig, W. Chem. Phys. Lett. 2009, 469.

(101) Flom, S. R.; Barbara, P. F. J. Phys. Chem. 1985, 89, 4489.

(102) Nishiya, T.; Yamauchi, S.; Hirota, N.; Baba, M.; Hanazaki, I. J. Phys. Chem. 1986, 90, 5730.
(103) Fürstenberg, A.; Vauthey, E. Photochem. Photobiol. Sci. 2005, 260.

(104) Sherin, P. S.; Grilj, J.; Tsentalovitch, Y. P.; Vauthey, E. J. Phys. Chem. B 2009, 113, 4953.

(105) Banerji, N.; Fürstenberg, A.; Bhosale, S.; Sisson, A. L.; Sakai, N.; Matile, S.; Vauthey, E. J. Phys. Chem. B 2008, 112, 8912.

(106) Grabowski, Z. R.; Rotkiewicz, K.; Rettig, W. Chem. Rev. 2003, $103,3899$.

(107) Galievsky, V. A.; Druzhinin, S.; Demeter, A.; Jiang, Y.-B.; Kovalenko, S. A.; Lustres, J. L. P.; Venugopal, K.; Ernsting, N. P.; Allonas, X.; Noltemeyer, M.; Machinek, R.; Zachariasse, K. A. ChemPhysChem $\mathbf{2 0 0 5}, 6,2307$.

(108) Mohammed, O. F.; Vauthey, E. J. Phys. Chem. A 2008, 112, 3823.

(109) Kang, T. J.; Kahlow, M. A.; Giser, D.; Swallen, S.; Nagarajan, V.; Jarzeba, W.; Barbara, P. F. J. Phys. Chem. 1988, 92, 6800.

(110) Herbich, J.; Kapturkiewicz, A. J. Am. Chem. Soc. 1998, 120, 1014.

(111) Banerji, N.; Angulo, G.; Barabanov, I. I.; Vauthey, E. J. Phys. Chem. A 2008, 112, 9665 .

JP903900B 